\title{
Actividade Física e Lazer - contextos actuais e ideias futuras
}

\author{
Jorge Mota \\ Faculdade de Ciências do Desporto e de Educação Física, \\ Universidade do Porto
}

https://doi.org/10.5628/rpcd.01.01.124

\section{INTRODUÇÃO}

$\mathrm{O}$ desporto e a actividade física são actualmente parte integral da vida social, sendo catalogados como os pressupostos de referência de um conjunto de valores e regras que representam em si a força geradora da sua dinâmica e importância. Embora o lazer seja um conceito complexo, com diferentes significados, dependendo do contexto sócio-cultural e do próprio indivíduo, podemos considerá-lo (27):
A. Lazer como tempo livre
B. Lazer como actividade recreativa
C. Lazer como atitude

Esta tentativa pedagógica de situar, ou esclarecer o significado do lazer, deixa antever, desde logo, o carácter dinâmico e de pluralidade de entendimentos e contextualizações passíveis e também possíveis de serem obtidos.

Não é possível menosprezar, neste contexto e num âmbito mais alargado das actividades de lazer, a existência de uma multiplicidade de lazeres que desencadeiam e exigem interpretações alargadas. É necessário considerar a existência de um fenómeno global de carácter sócio-económico e cultural à escala planetária, mas, com necessidades e nuances específicas em função das microsociedades que nos rodeiam (4).

De qualquer modo, o fenómeno do lazer e das suas práticas, na actualidade, parece não oferecer grande contestação pois elas não se constituem um privilégio duma minoria. Pelo contrário, o lazer é assumido pela sociedade em geral, sendo que o hedonismo é um dos suportes fundamentais da

cultura hodierna (7). Com efeito, o consumo generalizado (consumo de massas) transformou de forma significativa o hedonismo característico das sociedades mais abastadas num comportamento mais generalizado da população. É evidente que o culto do consumo, do tempo livre e do prazer se constituem como características definidoras do quadro social contemporâneo (3).

Não é de estranhar portanto, que o fenómeno do lazer concorra com o espaço e ritmo de vida quotidiana do indivíduo. Efectivamente, com a diminuição do tempo de trabalho, o aumento da escolaridade e as reformas antecipadas, as pessoas vêem-se confrontadas com um tempo que pretendem ocupar utilmente. Nesta perspectiva, o lazer surge, pois, com uma faceta importante, com um sentido objectivo, como uma forma de encontro e de compensação das necessidades sociais através de uma contenção social positiva (31).

Deste modo o espaço de lazer pode ser associado a um conteúdo que é livremente orientado para a realização da pessoa, encaminhando-se no sentido da auto-realização, isto é, os indivíduos querem ter a capacidade de moldar a sua existência de modo a explorarem, desenvolverem e utilizarem as suas capacidades, valores e interesses (29).

No mundo contemporâneo, as manifestações mais importantes das dinâmicas culturais são a diluição das fronteiras convencionais entre os diferentes níveis de conhecimento (9). Parece-nos relevante, a este propósito, compreender as relações e as realidades vigentes na funcionalidade das nossas sociedades e por isso perceber as potencialidades das práticas de lazer em face das mudanças sociais e culturais contemporâneas, traduzidas num 
desenvolvimento multifacetado e bastante complexo, contemplando as mudanças económicas associadas aos novos padrões de competividade, bem como a rapidez das alterações tecnológicas e dos sistemas de comunicação (28).

A actividade física enquanto fenómeno orientado para a realização do sujeito, parece ser um domínio onde a sociedade tem ganho uma maior consciencialização. Nessa medida, ela tem sido associada àquilo que é favorecer e condizente com os aspectos mais elevados do nível de qualidade de vida do sujeito, isto é, o seu bem-estar (23).

A ideia de qualidade de vida não pode ser dissociada do nosso bem-estar, logo das manifestações positivas que se exercem sobre a nossa existência, sendo que alguns dos factores mais importantes para um desenvolvimento polivalente do ser bio-psico-social são as actividade físicas recreativas (12).

As actividades físicas surgem pois, nesta perspectiva, como o maior beneficiário do aumento das circunstâncias materiais e do aumento do conhecimento público dos benefícios de um estilo de vida activo (11). Estas actividades possuem características muito próprias, diferindo dos restantes tipos de actividade física, especialmente daqueles que fazem parte da jurisdição do desporto federado. Hoje em dia já é possível verificar a existência no mercado do fitness de equipamento interactivo que integra a actividade física e a competição em redes interactivas locais.

Nesta perspectiva importa não esquecer que o futuro onde iremos agir é radicalmente diferente do presente, implicando que se consiga encarar a realidade segundo diferentes perspectivas (1). A capacidade de comunicar em instantes de uma ponta a outra do mundo, a facilidade de distribuição daquilo que se produz, vieram dar uma configuração totalmente inovadora ao mundo em que vivemos e, com isso, aos significados possíveis da própria existência do desporto e da actividade física na vivência do lazer (2).

\section{A ACTIVIDADE FÍSICA E 0 LAZER}

"A diferença entre o preto e o branco não é uma questão de cor, mas sim da quantidade de luz que reflectem.

Os termos são relativos não absolutos."

C. Sagan
A associação das práticas físicas no domínio das preocupações e actividades quotidianas do Homem, por um lado e, o lazer por outro, não é recente. É apenas marcada, no decurso dos séculos e das diferentes civilizações, de apostas e vivências totalmente diferenciadas.

Com efeito, as actividades lúdicas sempre se constituíram como uma parte integrante da vida dos homens (5). A satisfação das necessidades elementares e as práticas religiosas formavam uma unidade coerente, tornando-se difícil separar o trabalho, a religião e o divertimento (6).

$\mathrm{Na}$ Grécia, sociedade em que o trabalho era garantido pelos escravos, o estilo de vida permitido e dedicado à classe privilegiada (os cidadãos) estava concentrada no cultivo do espírito, na contemplação, sendo esta liberdade total de obrigações, condição fundamental para a natureza do Homem Livre. A ideologia Grega proclamava ainda a harmonia do corpo e do espírito. No entanto, a participação na vida cívica era exclusiva dos cidadãos (homens livres) e do sexo masculino (4).

A civilização Romana tinha como objectivo fundamental das práticas físicas os motivos higiénicos, bem como os recreativos. Pelo contrário, na idade média, muito pela relação e importânica adquirida pelo Cristianismo, a ideologia medieval passava pela preocupação marcada da alma esquecendo o corpo (6). Assim, na idade média, as comunidades rurais possuíam um elevado espírito de convivência comunitária muito pela influência da Igreja. A nobreza encontrava na caça, na equitação e nos jogos de combate (justas e os torneios) a sua forma privilegiada de ocupação, a qual definia também a sua condição social (4).

Por seu lado, as formas de ocupação dos tempos livres nas sociedades industriais e pós-industriais acompanham a expansão económica, resultado da revolução empreendida pelo processo de industrialização (18). O lazer cria também postos de trabalho emergindo como uma estrutura economicamente rentável com enormes potencialidades de desenvolvimento e exploração (3). O lazer transformou-se numa indústria. Vive como muitas outras componentes da vida e estrutura social a era da globalização; desde os parques temáticos, às cadeias de restaurantes, passando 
pelos cinemas multiplex (10).

Neste contexto, o lazer e por consequência a própria actividade física. Passam também a constituir-se como um novo mercado, por sinal bastante lucrativo (26). Por paradoxo estas estruturas clamam pela intensificação das autonomias individuais, na qual a perspectiva assenta numa lógica singular, a de que cada indivíduo desenvolve as suas próprias percepções de ver a realidade envolvente. Não se procura em última análise o desenvolvimento pessoal do sujeito, mas assiste-se a uma luta feroz e mesmo a uma ditadura do marketing e do consumo, já que o sinal de riqueza dos nossos dias não é o da existência de tempo livre, mas sim o do consumo (6). É preciso reconhecer que a profunda alteração das sociedades industrializadas nos últimos 50 anos, gerando a sociedade de informação, trouxe consigo uma padronização dos hábitos que deixa pouco espaço à livre expressão, desvalorizando, contrariamente, aquilo que efectivamente veicula, o que há de específico nas pessoas (6).

Do ponto de vista da actividade física/desportiva as adaptações face às novas realidades têm sido particularmente profícuas. A sociedade contemporânea surge de uma forma muito marcada com uma ligação da actividade física ao lazer, ou de uma cultura do corpo nas actividades do lazer. Esta não pode ser dissociada de um outro factor ou conceito que é o da saúde, bem como o conjunto de referências, por exemplo de qualidade de vida e bemestar, que lhe estão associados (15).

Duas grandes alterações parecem ser visíveis. A primeira reporta-se à sua relação como tipo de actividade e a segunda, o da sua natureza. Um dos grandes crescimentos verificados nas práticas do "ser activo" tem sido particularmente intensa nos desportos individuais comparativamente aos de equipa, perseguindo objectivos ligados ao exercício e à saúde, bem como à aventura, à atracção e à natureza.

Para Elias (8), o elemento fundamental de satisfação no lazer é a produção de tensões de um tipo particular, o "desenvolvimento de uma agradável tensão-excitação". As actividades de lazer proporcionam (de uma forma simples ou complexa, a um nível mais elevado e por um período efémero) a erupção de sensações fortes e agradáveis habitualmente ausentes das rotinas quotidianas. A sua função não é, como muitas vezes se pensa, a libertação de tensões, mas sim a renovação dessa medida de tensão, o que constitui um factor importante da saúde mental (8). Ainda segundo este autor, mais do que relaxamento, as pessoas esperam, das suas actividades de lazer, estimulação, alegria, excitação e um despertar emocional agradável. Uma segunda evidência reporta-se a uma prática mais generalizada, mas também realizada em espaços mais restritos, já que os espaços mais tradicionais (parques e campos de jogos) estão claramente desadaptados face às realidades vigentes. Esta adaptação das modalidades, pelo aparecimento de novas actividades ou pelas adequações de regras e números de jogadores a novos espaços, encontra-se claramente justificada por aquilo que poderíamos definir como uma adequação da prática desportiva à realidade urbana. Como expressão ou resultado destas tendências, as actividades de recreação têm-se tornado em actividades gradativamente mais informais e individuais, ou em propostas envolvendo apenas amigos e familiares, por oposição aos compromissos dos jogos e actividades formais (26). Quando o objectivo é encorajar os jovens, em particular, e as pessoas em geral, a serem activos ao longo da vida, o ênfase transfere-se dos resultados para a qualidade da experiência durante a participação (22). Se a experiência for positiva ou divertida, se a experiência valorizar as percepções da criança e do adolescente, então com mais probabilidade, os jovens manterão a actividade para o resto da sua vida (20).

Por isso, a visão mais recente em relação à prescrição da actividade física, a qual associa níveis mais moderados de actividade à saúde (25), parece ser mais consistente com a realidade das práticas correntes, pois podem ser realizadas fora do contexto tradicional e/ou formal e são extraordinariamente importantes na efectiva generalização da actividade como actividade de recreação, entendido este como um espaço autónomo de realização pessoal (21). Poderíamos resumi-las nos seguintes pontos:

1. são enfatizados os benefícios relacionados com a saúde das actividades de intensidade moderada; 2. é atribuído significado acrescido à acumulação de 
períodos de actividade física desenvolvida em momentos mais curtos e intermitentes de actividade. Estes são considerados como um conteúdo suficientemente significativo para uma influência positiva no contexto da saúde relacionada com a actividade física.

O usufruto das actividades de lazer é determinado mais por factores subjectivos como a liberdade e percepção de competência na realização daquelas práticas, do que por factores objectivos como a prática em si mesmo ou a capacidade financeira do sujeito (Shaw, 1984). Neste sentido o ponto central é o do sentimento positivo que o sujeito tem para com a actividade e a partir daqui envolver-se na sua prática (31).

Veja-se, por exemplo, que os tipos de actividade física mais populares entre a população adulta activa são aqueles que podem ser realizados em grupo ou sozinho, sem o enquadramento especializado ou de uma classe formal. Efectivamente a percentagem da população que participa em programas formais e organizados é pequena comparada com aquela que se exercita sozinha de forma espontânea (14).

Deste modo, a adaptação dos desportos para espaços mais restritos aumenta o número de praticantes e, contrariamente a uma limitação quantitativa que lhe poderia estar associada, favorece a democratização da prática desportiva. De igual modo quando as modalidades restringem ou diminuem o número de jogadores (ex: street basquete), concretiza-se uma opção pela individualidade em detrimento do colectivo. Se este facto por um lado poderia apresentar conotações menos positivas, também é verdade que esta adaptação é positiva por facilitar a prática a um maior número de pessoas. Contudo a actividade desportiva no âmbito do lazer não pode deixar de ser entendida como uma manifestação importante das aspirações e valores individuais, mas particularmente dos sociais (8). Com efeito, a actividade física, mais concretamente preocupações e valores que lhe estão habitualmente conotados, traduzem em si mesmo um conjunto de preocupações mais profundas da vivência corporal e da expressão do sujeito enquanto indivíduo (13). A forma como mudamos o corpo, como protagonizamos os gestos, ou desenvolvemos simbolismos, são consequências de um desejo mais profundo de desenvolvimento ou de mudança da própria identidade. Nietzche dizia que há mais razão no teu corpo do que na própria essência da sabedoria. A eclosão de todos estes aspectos é de tal forma evidente que o corpo passa a ser também uma via de representação social. As actividades físiscas mais representativas do "fitness" permitem-nos seguir a trajectória desta representação. Não basta ser saudável, hà que parecê-lo. È a asssociação entre a saúde e o aspecto físico (corpo musculoso e forte). Trata-se de uma nova "moral do corpo", em que o arquétipo triunfante oferece o corpo cultivado pelo ginásio (13).

Em síntese, a actividade física e desportiva é preconizada como um dos meios de compensação dos efeitos nocivos do modo de vida da sociedade hodierna. Ela surge como o potencial catalizador da utilização do tempo livre, o que tem sido referenciado como um fenómeno não negligenciável de afirmação na sociedade contemporânea.

\section{O FUTURO}

"O futuro não tens de o prever, tens de o permitir." A. Saint-Exupéry

O maior problema ligado ao futuro do lazer é o de que estamos sempre preparados para o trabalho mas não para o tempo livre (6). De acordo com este autor, muitos indivíduos sabem trabalhar mas não sabem usufruir bem o seu tempo livre, porque porque não existe um modelo social baseado no tempo livre, já que todos os modelos de sociedade ocidental são baseados no trabalho. Poderiamos afirmar que o ser humano está muito perto de alcançar aquilo que sempre almejou. Somos capazes de produzir cada vez mais com cada vez menos trabalho. Isto adequase a um princípio, importante de desenvolvimento ontológico do ser humano. O Homem sempre tentou viver o mais tempo possível, sofrendo o menos possível e trabalhando o menos possível (6). Assim, discutir o futuro do lazer e das suas práticas, particularmente das desportivas, significa também discutir os aspectos culturais, visto que uma qualquer política cultural que procure ser consistente, não pode deixar de levar em linha de conta o tempo livre e o seu imenso potencial 
educativo, ou, por outras palavras, discutir a necessidade de um processo educativo que não esqueça o lazer e a sua vivência (21).

Não pode ser descurado também a importância do lazer e das práticas de actividade física como factor de integração social, seja das minorias étnicas, sociais (mulheres e idosos) (18).

Por outro lado, a necessidade de novas práticas tenta dar resposta ao florescer do culto do corpo, componente vital da sociedade de consumo que caracteriza os nossos dias. Aqui o mais importante é a compreensão da colonização mercantilista do tempo livre como tempo de consumo (9). É, não raramente o privilégio do consumo por oposição a uma vivência e usufruto equilibrados do nosso tempo livre (24).

Deste modo podemos isolar cinco tendências na evolução das exigências sobre a actividade física no contexto do lazer ${ }^{(19)}$ :

1. A procura da autonomia, que tem como consequência a rejeição das grandes organizações, as quais lidam com os indivíduos com um excesso de restrições e regulamentações;

2. A procura do prazer, da alegria e realização pessoal, em detrimento do tradicional ascetismo desportivo;

3. A procura da vitalidade e da "forma" com o intuito de garantir o bem-estar físico;

4. A procura de uma rica comunicação interindividual, pela participação em pequenos e informais grupos por oposição às grandes organizações e instituições;

5. A procura de uma harmonia entre as qualidades mentais e físicas, como envolvimento natural e urbano.
A este propósito não é de descurar aqui a importância dos meios de informação em geral. Efectivamente eles criam, em grande medida, muitas das necessidades do indivíduo. Objectivamante ninguém tem necessidade daquilo que ignora, daí a importância dos mecanismos e processos de informação na criação de uma realidade (16). Deste modo parece plausível entender que as orientações das tendências no âmbito das actividades físicas e de recreação salientam as orientações do indivíduo enquanto consumidor. Efectivamente a realidade contemporânea exige um conjunto de estratégias que abranjam as múltiplas facetas da realidade desportiva presente, as quais, naturalmente, permitirão a produção e o desenvolvimento de serviços, quer quantativa quer qualitativamente adaptados às múltiplas exigências, motivações e interesses que caracterizam os consumidores. A natureza da cultura comercial contemporãnea é composta por muitos mercados intensos, nos quais a sobreprodução e a permanente renovação são uma exigência e, como tal, a regra (17). Neste sentido a actividade física enquanto prática de lazer terá, concerteza, um campo de múltiplas manifestações no futuro, no qual a maior dificuldade será o da gestão equilibrada dos interesses e motivações que lhe estão associados. Assim deverá gerir o difícil equilíbrio da sua vertente associada aos padrões de qualidade de vida, saúde e bem-estar das populações, por um lado e, por outro, da sua componente de objecto de consumo e de comércio que condiciona a liberdade de escolha e , com frequência a suas próprias manifestações e vivências. 


\section{REFERÊNCIAS BIBLIOGRÁFICAS}

1-Baczko, B.: Utopia para um futuro possível. Ciclo de conferências. 1995.

2-Bento, J.O.: Desporto e humanismo. O campo do possível. Editora da Universidade do Estado do Rio de Janeiro. 1998. 3-Bétran, J.O.; Bétran, M.U.: La crisis de la modernidad y la advenimiento de la postmodernidad: el deporte y las prácticas fisicas alternativas en él tiempo de ocio activo. Apunts Educació Fisica Y Deportes, 41: 10-29. 1995.

4-Camargo, L.O..: Educação para o lazer. Editora Moderna. São Paulo, Brasil. 1998.

5-Crespo, J.: O lazer e a recreação das populações. In: O desporto no século XXI. Edições Câmara Municipal de Oeiras. 1987.

6-De Masi, D.: O Futuro do Trabalho - Fadiga e òcio na Sociedade Pós-Industrial. José Olympio Lyd ( $3^{\text {a }}$ ed.). Rio de janeiro, 2000

7-Debord, G.: A sociedade do espectáculo. Mobilis in mobile. Lisboa, $2^{\text {a }}$ Edição. 1991

8-Elias, N.: Em busca da excitação. Edições Difel, Lisboa. 1992. 9-Featherstone, M.: Cultura do consumo e pós-modernismo. Studio Nobel. São Paulo, Brasil. 1995.

10-Featherstone, M.; Turner, B.S.: Body and society: an introduction. Body and Society, 1(1): 1-12. 1996.

11-Glyptis, S.: Leisure lifestyle: present and future. In: Physical activity and health. N.G. Norgan (ed.). Human Kinetics Publishers, Illinois. Pp: 230-245. 1992.

12-Guardia, C.V.: Leisure and socio-economic development. In: New routes for leisure. Actas do Congresso Mundial do Lazer.

Edições do Instituto de Ciências Sociais, Lisboa. 1994, pp: 443-455. 13-Gubern, R.: El cuerpo deseñado. El pais, 16. 1988.

14-Iverson, D.C.; Fielding, J.E.; Crow, R.S.; Christenson, G.M.: The promotion of physical activity in the United States population. The status of program in medical, worksite, community, and school settings in public health reports. Journal of the U.S. Public Health Service, 100(2). 1985. 15-Kooistra, J.: The format of knowledge. In: New routes for leisure. Actas do Congresso Mundial do Lazer. Edições do Instituto de Ciências Sociais, Lisboa. 1994, pp: 19-34. 16-Laborit, H.: O Homem e a cidade. Iniciativas Editoriais, Lisboa. 1973.

17-Laermans, R.: Leisure as "making time": some sociological reflections on the paradoxical outcomes of individualization. In: New routes for leisure. Actas do Congresso Mundial do Lazer. Edições do Instituto de Ciências Sociais, Lisboa. 1994, pp: 61-74.
18-Liikkanen, M.: Leisure moral and leisure meanings. In: New Routes for Leisure. Actas do Congresso Mundial do Lazer. Edições do Instituto de Ciências Sociais, Lisboa. 1994, pp: 85-98. 19-Loret, A.: The needs and motivations of sport demanding. In: Sport, leisure and physical education trends and developemnt. Meyer \& Meyer Verlag, Aachen. 1994, pp: 86-94 20-Martens, R.: Turning kids on to physical activity for a lifetime. American Academy of Kinesiology and Physical Education, 48: 303-310. 1996.

21-Mota, J.: A actividade física no lazer. Reflexões sobre a sua prática. Lisboa, Livros Horizonte. 1997a

22-Mota, J.: O valor da actividade física para uma educação de estilos de vida. In: A escola cultural e os valores. II Congresso da AEPEC. Colecção Mundo de Saberes, Porto Editora. 1997b, pp: $169-176$.

23-Mota, J.: O idoso, a actividade física e a qualidade de vida. In: A recreação e lazer da população com necessidades especiais. Actas do Seminário. Faculdade de Ciências do Desporto e de Educação Física da Universidade do Porto. 2000, pp: 126-131.

24-Opaschowski, H.W.: Das Freizeitprofil öffentlicher Bader: Was Kann Animation Leisten? Archiv des Baden Wesens, 3: 71-85. 1995.

25-Pate, R.R.; Prat, M.; Blair, S.N.; Haskell, W.L.; Macera, C.A.; Bouchard, C.; Buchner, D.; Ettinger, W.; Heath, G.W.; King, A.C.; Kriska, A.; Leon, A.S.; Marcus, B.H.; Morris, J.; Paffenbarger, R.S.; Patrick, K.; Pollock, M.L.; Rippe, J.M.; Sallis, J.; Wilmore, J.H.: Physical activity and public health. A recommendation from the centers for disease control and prevention and the American College of Sports Medicine. JAMA, 273(5): 402-407. 1995.

26-Roberts, K.: The three societies of leisure. In: New Routes for Leisure. Actas do Congresso Mundial do lazer. Edições do Instituto de Ciências Sociais, Lisboa. 1994, pp: 429-442.

27-Russel, R.V.: The context of contemporary leisure. Human Kinetics Publishers. Champaign, Illinois. 1996.

28-Séguéla, J.: O futuro tem futuro. Europa-América. 1988.

29-Sharma, V.: Leisure: a vedantic view. In: New Routes for Leisure. Actas do Congresso Mundial do lazer. Edições do Instituto de Ciências Sociais, Lisboa. 1994, pp: 35-44. 30-Shaw, S.M.: The measurement of leisure: a quality of life issue. Society and leisure, 71(1): 91-106. 1984.

31-Wankel, L.M.: Health and leisure: Inextricably linked. JOPERD (Special Issue). 1994, pp: 28-31. 